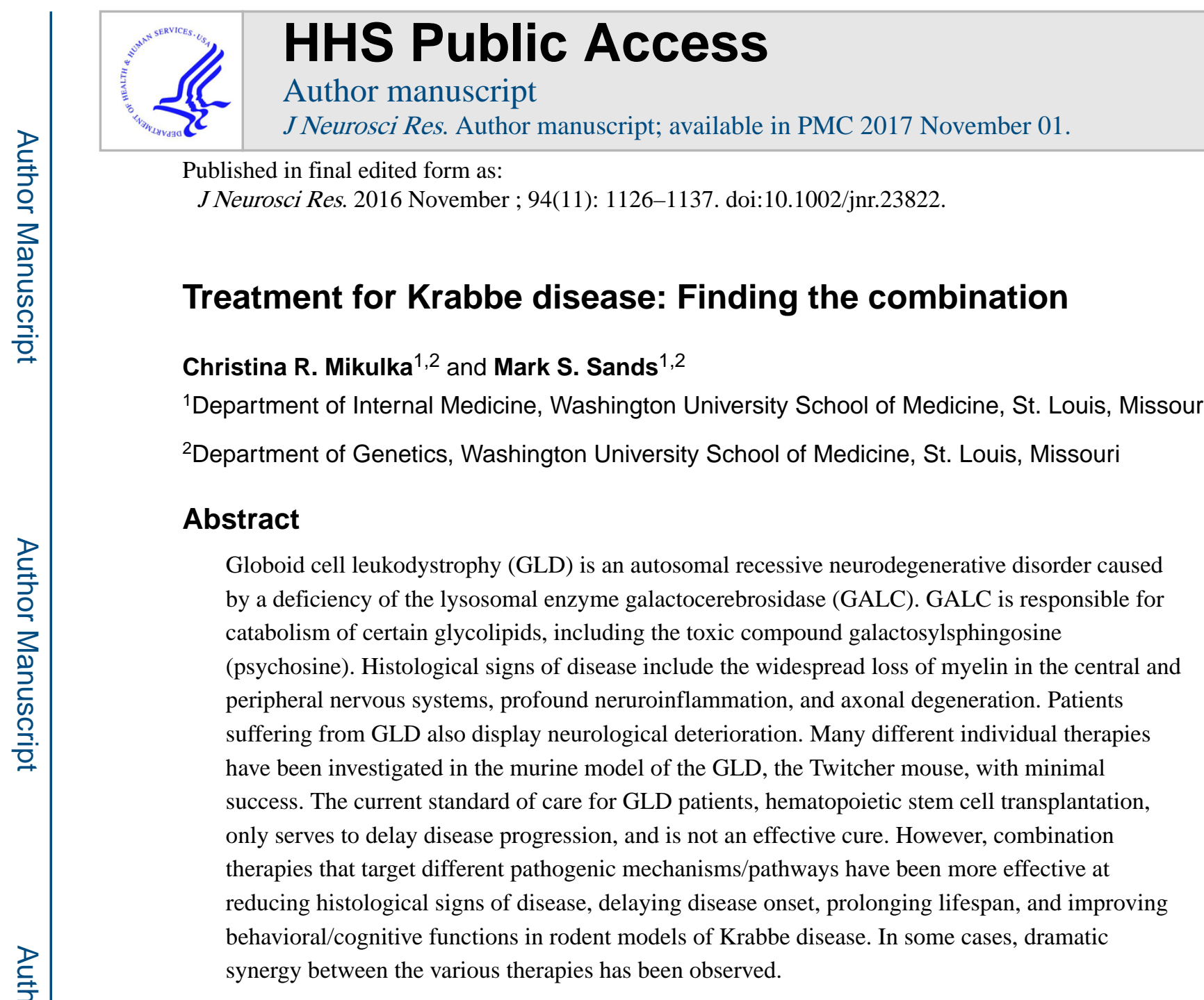

\title{
Keywords
}

Krabbe disease; bone marrow transplant; galactocerebrosidase; gene therapy; lysosomal storage disease

\section{Globoid Cell Leukodystrophy}

\section{Genetics}

Globoid cell leukodystrophy (GLD), or Krabbe disease (Krabbe, 1916; OMIM \#245200), is an autosomal recessive disorder, caused by a deficiency of galactocerebrosidase (GALC) activity (Suzuki and Suzuki, 1970). The majority of patients have the infantile form of GLD, with an incidence of 1-2 per 100,000 live births (Suzuki, 2003). Cases of juvenile- and adultonset GLD have been reported, but are more rare (Kohlschütter, 2013). However, the incidence of disease varies widely between countries, as does the most prevalent diseasecausing mutation (Suzuki, 2003).

Corresponding author: Mark S. Sands, Ph.D., Washington University School of Medicine, Department of Internal Medicine, Box 8007, 660 South Euclid Avenue, St. Louis, MO 63110, (314) 362-5494 (office), (314) 362-9333 (fax), msands@ dom.wustl.edu.

Role of authors: CRM and MSS conceived the design of the paper. CRM wrote the paper.

Conflict of interest statement: We have no conflicts of interest to report. 
Over 70 disease-causing variants have been found in the human $G A L C$ gene (chromosome 14q31), including missense and nonsense mutations, insertions, and deletions (Tappino et al., 2010). Many of the disease-causing variants in $G A L C$ result in single amino acid changes to residues buried within the folded protein (Deane et al., 2011). These amino acid changes often result in misfolding of the protein, and lead to early degradation (Deane et al., 2011). Due to the wide variety of disease-causing variants, there is also a broad range of GALC activity in the affected population (Suzuki, 2003). Unfortunately, there is poor genotype:phenotype correlation, and anticipating disease onset is difficult (Suzuki, 2003; Duffner et al., 2011; Fiumara et al., 2011). The only clear exception to this is a $30 \mathrm{~kb}$ deletion, which results in no enzyme activity, and is predictive of severe early-infantile onset (Luzi et al., 1995; Suzuki, 2003). Other variants result in decreased ability to interact with activating factors, thus lowering enzyme activity; these variants often lead to a milder disease phenotype (Deane et al., 2011). A better understanding of the effects of different variants will allow for more accurate genotype:phenotype correlation.

\section{Biochemistry}

GALC is ubiquitously expressed and its activity is localized to the lysosomes. GALC is responsible for the hydrolysis of galactosylated lipids, including galactosylceramide, a glycolipid found in central and peripheral myelin, and galactosylsphingosine (psychosine), a cytotoxic lipid (Lee et al., 2006). Galactosylceramide does not accumulate in the absence of GALC activity, and it has been suggested that this is due to the presence of other enzymes capable of degrading galactosylceramide (Kobayshi et al., 1985). However, using a model deficient in both GALC and acid $\beta$-galactocidase, Tohyama et al. (2000) found that doubledeficient mice still had low levels of galactosylceramide. This lead to the hypothesis that the extensive loss of myelin and oligodendrocytes in Krabbe disease could be contributing to the lack of accumulation of galactosylceramide, rather than alternate degradation pathways. However, psychosine can only be hydrolyzed by GALC. GALC deficiency results in accumulation of psychosine, which is toxic to all cell types (Tanaka and Webster, 1993; Jatana et al., 2002; Zaka and Wenger, 2004; Lee et al., 2006; Castelvetri et al., 2011). Oligodendrocytes are particularly susceptible to psychosine toxicity, possibly due to the fact that psychosine is primarily synthesized in these cells (Baumann and Pham-Dinh, 2001; Jatana et al., 2002; Haq et al., 2003).

The mechanism of psychosine toxicity remains unclear. Both receptor-mediated and membrane-based mechanisms for toxicity have been proposed (Im et al., 2001; White et al., 2009; Hawkins-Salsbury et al., 2013). There is compelling evidence that psychosine toxicity is not mediated by a receptor, but through membrane interactions (White et al., 2009). It was shown that psychosine is localized to lipid microdomains and disrupts their normal architecture (White et al., 2009). By using the enantiomer of psychosine (ent-psy), it was shown that apoptosis is induced by high levels of either psychosine or ent-psy, indicating that the mechanism of cell death is not enantioselective. It was also shown that both stereoisomers integrate into, and disrupt artificial lipid membranes, supporting the hypothesis that toxicity is through a membrane-based method (Hawkins-Salsbury et al., 2013). 
Under normal conditions, the level of psychosine in the brain is very low, due to the activity of GALC (Won et al., 2013). However, in GALC-deficient conditions psychosine accumulates in various tissues, and can account for as much as 50\% of total cerebrosides (Won et al., 2013). Analysis of tissues from infantile GLD patients shows high levels of psychosine in the brain, spinal cord, and sciatic nerve, but lower levels in somatic organs (Kobayashi et al., 1988). The "psychosine hypothesis" states that the accumulation of psychosine in GLD is the primary cause of the pathological signs of the disease (Miyatake and Suzuki, 1972). Supporting this hypothesis, in vitro studies show that treating cells with psychosine increases pro-apoptotic factors, promotes DNA fragmentation, and inhibits oligodendrocyte growth and maturation (Jatana et al., 2002; Haq et al., 2003). In addition, when injected into rat brains, psychosine leads to the formation of globoid cells, much like those seen in GLD (Andrews and Menkes, 1970).

\section{Clinical and Histological Signs}

Onset of infantile GLD is typically seen within 3 to 6 months after birth, and is first characterized by irritability, and loss of muscle tone (Suzuki, 2003; Lee et al., 2006). Other signs soon develop, including regression of motor development, convulsive seizures, blindness, hypertonic fits, and vomiting; death typically occurs before 2 years of age (Suzuki, 2003; Lee et al., 2006; Kohlschütter, 2013). GLD is characterized as a demyelinating disease due to the putative loss of oligodendrocytes. Other forms of GLD, juvenile and adult-onset, are less rapidly progressing, perhaps due to the higher levels of GALC activity than are typically seen in infantile-onset cases. Juvenile-onset GLD typically presents between 3-8 years after birth, with common symptoms including vision loss, ataxia, and regression of motor skills (Suzuki, 2003). Adult-onset can present much later, sometimes after 40 years; patients develop paraparesis or an unsteady gait, but can have a typical lifespan (Suzuki, 2003).

Characteristic histological features of GLD include accumulation of multinucleated macrophages, or globoid cells, loss of myelination in the central and peripheral nervous systems, axonal degeneration, gliosis, neuroinflammation, and death of oligodendrocytes (Jatana et al., 2002; Suzuki, 2003; Potter et al., 2013; Teixeira et al., 2014).

Although Krabbe disease is a simple monogenic disease, it has a broad spectrum of clinical signs. Due to the complex disease presentation, there are many possible therapeutic targets. Correcting the lack of functional GALC is the most straightforward therapeutic approach, either by directly supplying active enzyme to the CNS through enzyme replacement or gene therapy, or by transplanting GALC-expressing donor cells. Reducing the accumulation of psychosine by inhibiting its synthesis (substrate reduction therapy), is another possible strategy. Targeting secondary pathogenic mechanisms, such as neuroinflammation and oxidative stress could also be used to treat GLD, although these strategies will not fully correct the disease since the enzyme deficiency is not addressed. It is likely that the most effective treatment for Krabbe disease will involve some combination of the above mentioned approaches. 


\section{Animal Models}

\section{Murine}

The primary model used to study GLD is the murine model, commonly referred to as the Twitcher mouse. The Twitcher mouse is a naturally-occurring mutant that contains a premature stop codon (W339X) in the GALC gene, which results in complete loss of enzymatic activity (Kobyashi et al., 1980; Sakai et al., 1996; Teixeira et al., 2014). Mice heterozygous for the Twitcher mutation are phenotypically normal. Homozygous Twitcher mice have similar biochemical and pathological signs of disease as GLD patients, making it an effective model for the study of the pathogenesis and treatment of the disease (Kobyashi et al., 1980; Suzuki and Suzuki, 1983). Psychosine accumulates in many tissues of the Twitcher mouse, including brain, sciatic nerve, and serum (White et al., 2009)

The first signs of murine GLD are not apparent until postnatal day (PND) 15 (Taniike and Suzuki, 1994). Until this point, affected Twitcher mice are indistinguishable from their heterozygous and wild-type littermates (Duchen et al., 1980). The progression of the disease is rapid, and the median lifespan of Twitcher mice is 36-40 days (Kobyashi et al., 1980; Duchen et al., 1980; Suzuki and Suzuki, 1983). Due to the rapid reproduction of Twitcher mice, this model is excellent for studies that require a large number of affected animals. The majority of the pre-clinical testing has been done in this murine model.

Another murine model, the trs mouse, was developed using homologous recombination (Luzi et al., 2001). These mice contain the variant $\mathrm{H} 168 \mathrm{C}$ on a FVB/N background, resulting in an 80-90\% reduction in GALC activity (Luzi et al., 2001). Trs mice have increased levels of psychosine in the brain, however, the rate of accumulation is slower than that observed in Twitcher mice (Luzi et al., 2001). At PND 49, these mice display demyelination in both the CNS and PNS, and though there is macrophage infiltration, it is not as severe as that seen in the Twitcher model (Luzi et al., 2001).

Trs mice homozygous for the mutation are indistinguishable from their heterozygous and wild-type litter mates for the first 25-30 days, but begin to show obvious signs of tremors and hind-limb weakness at this point (Luzi et al., 2001). These mice have an average lifespan of 50 days, but there is considerable variability, with the lifespan ranging from 40-63 days (Luzi et al., 2001). Due to the higher levels of GALC activity, later-onset of disease, and more variable lifespan, trs mice may be a more accurate model of juvenile-onset rather than infantile-onset GLD.

\section{Canine}

Canine GLD was first described in a case study in the 1960s, present in both Cairn and West Highland white terriers (Fletcher et al., 1972). Subsequently, a breeding colony was established and Victoria et al., (1996) cloned the terrier cDNA and identified the causative variant in the canine GALC gene. Unlike the Twitcher mouse, where signs of disease are uniform from mouse to mouse, disease onset in the canine model is more variable (Victoria et al., 1996). This variability in the canine disease is likely due to the fact that the canine must be maintained as an outbred colony, whereas the Twitcher mouse is maintained as an inbred strain. The first signs of canine GLD appear between one and three months, and the 
dogs typically become moribund between eight and nine months (Victoria et al., 1996). Similar to the murine model and to GLD in humans, affected canines have a decrease in myelination and an accumulation of globoid cells (Victoria et al., 1996; Wenger et al., 1999). Affected animals also have significantly higher psychosine levels when compared to unaffected animals (Wenger et al., 1999).

Due to the large size of this model, it is useful for MRI comparisons to the human disease (Wenger et al., 1999). The dog model is also useful for studying the effects of in utero bone marrow transplantation, modeling drug diffusion within the CNS, and for collecting repeated or serial tissue samples from the same animal (Wenger et al., 1999). Using the canine model for therapy studies also serves as an intermediate species for the translation of therapies to the clinic.

\section{Primate}

A nonhuman primate model was cultivated after a rhesus macaque was born showing signs of GLD (Basken et al., 1998). A colony was established, and Luzi et al. (1997) cloned the GALC cDNA and determined the disease-causing variant in the rhesus model. It has been suggested that the rhesus model will be useful for investigating in utero bone-marrow transplantation and gene therapy (Luzi et al., 1997). Data from a non-human primate model are often necessary before therapies are translated into the clinic. However, the utility of this model is limited due to the low reproduction rate of rhesus, and the prohibitively expensive maintenance costs.

\section{Single-Modality Therapies \\ Bone marrow transplant}

The current standard of care for GLD is hematopoietic stem cell transplantation (HSCT), derived from bone marrow (BMT) or umbilical cord blood (UCB). There has only been modest success using HSCT to treat patients with infantile GLD, however, treating adolescent-, juvenile- or adult-onset has proved more successful (Krivit et al., 1998). It is theorized that GALC-positive donor cells of hematopoietic origin can migrate to the CNS and provide continuous, albeit low levels, of GALC. GALC secreted by the donor cells can then be taken up by deficient cells in the CNS either by the mannose-6-phosphate (M6P) or the mannose receptors on the surface of every cell of cells of the reticuloendothelial system, respectively. After binding to a cell-surface receptor, GALC can be endocytosed and transported via the endosomal system to the lysosome, where it uncouples from the receptor (Neufeld and Fratantoni, 1970; Kornfeld, 1992). This process, known as cross-correction (Neufeld and Fratantoni, 1970), is able to supply functional GALC to cells of the CNS. For example, it was demonstrated that oligodendrocytes derived from Twitcher mice survived and were able to properly myelinate axons when transplanted into the Shiverer mouse, which is deficient in myelin basic protein (Kondo et al., 2005). These data suggest that sufficient GALC activity from the host cells (Shiverer) is taken up by the transplanted oligodendrocytes to correct the metabolic defect. 
The first experiments using Twitcher mice showed that BMT on PND 10 with lethal irradiation significantly increased lifespan to an average of 80 days (Yeager et al., 1984). Treated mice had improved myelination; however, there was no decrease in globoid cell number in the brain, or in tremor severity (Yeager et al., 1984). A later study showed that BMT increased GALC activity in a variety of tissues, including the brain, spleen, and bone marrow (Hoogerbrugge et al., 1988). However, some more recent studies have shown that BMT alone using non-myeloablative conditioning does not significantly increase GALC activity in the brain, suggesting that BMT may attenuate disease through additional mechanisms (Reddy et al., 2011).

If initiated before the onset of symptoms, HSCT can provide some benefit to patients with infantile GLD. It has been shown to decrease the severity of disease, including a reduction of seizure activity, increased motor skills, and language development (Krivit et al., 1998). If the transplant is tolerated, some cases have reported circulating GALC activity levels similar to unaffected family members (Caniglia et al., 2002). Escolar et al. (2005) evaluated the efficacy of using UCB from unrelated donors. Asymptomatic newborns were transplanted with UCB, with partial HLA mismatch (Escolar et al., 2005). All patients that engrafted survived, and GALC activity levels in peripheral blood were at normal levels post transplantation (Escolar et al., 2005). Although there were significant improvements in motor-skill development compared to untreated patients, developmental delay remained apparent (Escolar et al., 2005).

Patients undergoing HSCT are at risk of developing severe graft versus host disease (GVHD) an inflammatory response caused by the donor cells. While the risks associated with HSCT have decreased due to better HLA typing and the use of UCB, there are still significant risks to this treatment. This is an important consideration, since HSCT is not curative. Although some cases of HSCT have reported a decrease in disease symptoms, some patients die shortly after HSCT is performed (Caniglia et al., 2002). HSCT performed in utero has been largely unsuccessful, with the majority of patients dying shortly after birth, or during the third trimester of development (Bambach et al., 1997; Caniglia et al., 2002). This is likely due to partial or transient hematopoietic engraftment when transplantation is performed without conditioning. As discussed above, HSCT was thought to provide low levels of GALC to the CNS long after transplantation, in a cross-corrective fashion. However, recent studies show that HSCT also provides an immunomodulatory effect, by reducing the level of neuroinflammation (Reddy et al., 2011). When used in combination with viral-mediated gene therapy, HSCT reduces the levels of activated microglia, as well as the numbers of CD4 and CD8 positive T-cells in the brains of treated Twitcher mice (Reddy et al., 2011). Although the mechanism by which HSCT provides an immunomodulatory function is not known, it is likely that the therapeutic effects of HSCT result from both supplying GALC activity and also decreasing neuroinflammation.

The hematopoietic system is also a target for ex-vivo gene therapy since BMT is the standard of care for Krabbe disease. In this case, autologous hematopoietic stem cells could be genetically modified to express GLAC, then transplanted back into the same patient. This could supply a persistent source of GALC activity and essentially eliminate GVHD. Unfortunately, unregulated expression of GALC in hematopoietic stem cells appears to be 
toxic, thus decreasing the engraftment of the transduced cells. To overcome this limitation, Gentner et al., (2010) introduced a microRNA target into the cDNA encoded by a lentiviral vector, which resulted in the developmental regulation of GALC in the hematopoietic compartment. This restored hematopoietic reconstitution and allowed for GALC expression in more fully differentiated blood cells. Although engraftment and persistent GALC expression were restored, the transplanted mice lived no longer than animals receiving a transplant from a GALC-positive syngeneic animal (Yeager et al., 1984).

\section{Enzyme Replacement Therapy}

Enzyme replacement therapy (ERT) is now the standard of care for several lysosomal storage diseases (Desnick and Schuchman, 2012). ERT takes advantage of M6P receptormediated transport, in which M6P modified recombinant enzyme can be endocytosed by enzyme-deficient cells expressing the M6P receptor on their surface (Neufeld and Frantantoni, 1970; Kornfeld, 1992). This strategy will provide a transient source of active GALC to deficient cells and tissues, and has been evaluated in the Twitcher model. Weekly intraperitoneal (IP) injections of recombinant GALC were able to extend the lifespan of Twitcher mice to 47 days (Lee et al., 2005). Interestingly, the increase in lifespan was observed whether treatment started at PND 10 or at PND 20 (Lee et al., 2005). It is unlikely that systemic ERT through an IV or IP route will provide significant long-term efficacy since GALC does not cress the blood brain barrier.

Delivery of GALC through a single intracerebroventricular (ICV) injection resulted in GALC activity throughout the CNS, though highest levels were localized at the injection site (Lee et al., 2007). Mice treated in this study had significantly lower psychosine levels than untreated animals when measured 24 hours after treatment, and those given a dose of $6 \mu \mathrm{g}$ GALC survived to approximately 46.5days (Lee et al., 2007). The minimal increase in lifespan was likely due to the fact that ERT was administered at a single time-point. It is likely that the therapeutic efficacy would be much greater if the enzyme were administered repeatedly. However, repeated administration would require regular invasive procedures or the placement of an implantable pump. Even with repeated administration, recombinant GALC would likely not diffuse throughout both the CNS and PNS, so multiple dosing sites would also be required.

\section{Viral-mediated gene-therapy}

The efficacy of CNS-directed gene therapy relies on the principle of cross-correction. With the current technology, only a relatively small proportion of cells can be transduced by a viral gene transfer vector. However, the transduced cells can then over-express GALC which can be secreted and correct adjacent cells. CNS-directed, adeno-associated viral (AAV)mediated gene therapy has been shown to increase enzyme activity and improve behavioral and cognitive functions in other murine models of lysosomal storage diseases (Skorupa et al., 1999; Frisella et al., 2001; Passini et al., 2005; Passini et al., 2006). AAV-mediated gene therapy allows for delivery of $G A L C$ cDNA to enzyme-deficient cells, providing a persistent source of enzyme to GALC-deficient tissues. The majority of AAV capsid proteins used to pseudotype vectors for CNS applications (AAV1, 5, 9, rh10) have a strong tropism for neurons (Asokan et al., 2012). Therefore, the neurons will supply the majority of cross- 
corrective enzyme. Although AAV-mediated gene therapy in the Twitcher mouse increased brain GALC activity to several-fold greater than normal, the histological and clinical benefit was not as great as that seen in other models (Rafi et al., 2005; Lin et al., 2005). Rafi et al. (2005) cloned GALC cDNA into an AAV 2 vector and pseudotyped it with the AAV 1 capsid protein (AAV2/1). Twitcher mice and twi-trs mice, animals containing the W339X mutation on a hybrid 129SVJ and FVB/N background, received ICV injections shortly after birth (Rafi et al., 2005). Treated Twitcher mice survived significantly longer than untreated animals, with lifespan extended by $40-50 \%$ (Rafi et al., 2005). Twi-trs mice had whole-brain GALC activity several fold higher than WT levels, and GALC was present in all areas of the brain, to varying degrees (Rafi et al., 2005). Levels of psychosine in twi-trs treated mice were significantly lower than in untreated animals, as were the levels of both GFAP-positive astrocytes and PAS-positive macrophages (Rafi et al., 2005).

In a similar study, Twitcher mice were given intracranial (IC) injections on PND 3 with either AAV2/2-GALC or AAV2/5-GALC (Lin et al., 2005). Whole-brain measurements of GALC activity indicated a several-fold increase compared to WT levels, in mice treated with AAV2/5-GALC. Mice treated with AAV2/2-GALC had whole-brain GALC activity at $~ 28 \%$ WT levels (Lin et al., 2005). Median lifespan of AAV2/5-GALC treated Twitcher mice was 52 days, significantly greater than those treated with AAV2/2-GALC, which survived on average 48 days (Lin et al., 2005). The AAV2/5-treated animals had improved motor performance compared to AAV2/2-treated animals, and both groups performed better than untreated or AAV2/2-GFP-treated control Twitcher mice (Lin et al., 2005). These results indicate that the AAV2/5 vector is more effective at improving disease phenotype that the AAV2/2 vector. This is consistent with the observation that the AAV5 capsid protein results in a greater distribution and higher level of transduction in the mouse brain, specifically in neurons and astrocytes, compared to the AAV2 capsid protein (Davidson et al., 2000).

Using AAV2/rh10-mGALC, Rafi et al. (2012) were able to extend the lifespan of Twitcher mice to an average of 57 days using a single IV injection on PND2. AAV2-rh10 is reported to cross the blood-brain barrier at a similar efficiency as AAV9, and transduce primarily neurons (Rafi et al., 2012). In this same study, it was shown that using a combination of ICV and IC delivery could further extend the lifespan to an average of 81 days, and a combination of ICV+ IC + IV extended average lifespan to 104 days (Rafi et al., 2012).

Recently, Rafi et al. (2015b) treated Twitcher mice on PND10-12 with a single tail vein injection of AAV2/rh10-mGALC. Treated mice survived significantly longer than untreated animals, and had a reduced kyphosis and tremors (Rafi et al., 2015b). Tissues from treated animals had GALC activity at or exceeding WT levels in brain, spinal cord, and sciatic nerve, when measured at PND45-64 (Rafi et al., 2015b). It is likely that the efficacy observed in this study is due to partial correction of both the peripheral and central nervous systems.

\section{Substrate Reduction Therapy (L-cycloserine)}

Therapies that do not directly address the enzymatic deficiency are not able to cure the disease, however, they could be useful in ameliorating disease phenotypes and extending lifespan. An alternative way to compensate for the low GALC activity is to inhibit the 
production of the cytotoxic molecule, psychosine. This approach is referred to as substrate reduction therapy (SRT) and has shown promise in other lysosomal storage diseases (Parenti et al., 2015). Although SRT is a promising approach, it will only slow the progression of disease. Because there is no current inhibitor for ceramide galactosyltransferase (CGT), the enzyme directly responsible for psychosine synthesis, enzymes further upstream must be targeted (LeVine et al., 2000). L-cycloserine is an irreversible inhibitor of serine palmitoyltransferase, an upstream enzyme in the psychosine synthesis pathway (Sundaram and Lev, 1984). Due to its being further upstream in the cerebroside synthesis pathway, Lcycloserine reduces the levels of several critical cerebrosides, in addition to psychosine (Sundaram and Lev, 1984). Treatment of pre-symptomatic Twitcher mice with L-cycloserine extended their lifespan by several days, with mice becoming moribund at PND 57, on average (LeVine et al., 2000). In addition, L-cycloserine-treated mice had decreased levels of astrocytosis; however, no significant increase in myelination was observed (LeVine et al., 2000).

\section{Anti-inflammatory therapies}

Because of the severe neuroinflammation present in GLD patients, several antiinflammatory therapies have also been tested. Twitcher mice have elevated levels of TNFa, eventually reaching levels as high as $70 \times$ WT levels by the terminal stage of the disease (Luzi et al., 2009). The phosphodiesterase inhibitor ibudilast has been shown to reduce TFNa and other inflammatory cytokines (Suzumura et al., 1999; Kagitani-Shimono et al., 2005). Twitcher mice treated daily with ibudialast starting at PND 30 were reported to have less severe signs of disease, including a reduced tremor and reduction in demyelination when compared to vehicle-treated Twitcher mice (Kagitani-Shimono et al., 2005). Despite these promising results, treatment of Twitcher mice starting at PND 15 did not result in an increased lifespan or significant improvement in signs of disease (Kagitani-Shimono et al., 2005).

A study by Luzi et al., (2009) tested the effect of several anti-inflammatory drugs on trs mice. Three separate anti-inflammatory drugs were tested; indomethacin and ibuprofen are both non-steroidal anti-inflammatory compounds, and minocycline has neuroprotective and anti-apoptotic properties (Luzi et al., 2009). These were first administered through the drinking water of the nursing mother, and continued postnatally for the life of the affected animals. All treatments were compared to BMT in trs mice, and cytokine levels were measured at PND 58 and terminal time points in treated mice (Luzi et al., 2009). All treatments increased lifespan an average of 11 days. Indomethacin was the most effective in reducing the levels of pro-inflammatory cytokines: levels of IL-6 were reduced by about half, and TFNa was reduced several-fold from those measured in untreated trs animals (Luzi et al., 2009). Although each anti-inflammatory treatment was able to reduce the levels of pro-inflammatory cytokines, none performed as well as BMT (Luzi et al., 2009).

\section{Antioxidant Therapy}

Due to the high oxidative stress seen in cells exposed to psychosine, antioxidant treatments have also been explored. Paintlia et al. (2015) hypothesized that psychosine accumulation could be altering vitamin D homeostasis, contributing to the demyelination seen in GLD 
patients and animal models. Therefore, heterozygous mothers and weaned Twitcher mice were fed a high vitamin $\mathrm{D}$ diet for the duration of their lives. The high vitamin $\mathrm{D}$ diet significantly extended lifespan to a mean of 50 days, and onset of tremor was delayed to PND 35 days (Paintlia et al., 2015). Treated mice had a slower rate of psychosine accumulation and reduced levels of demyelination compared to untreated animals (Paintlia et al., 2015).

\section{Oligodendrocyte transplant}

The rapid death of oligodendrocytes and other myelinating cells is a hallmark of GLD, and maintaining the myelinating cell population has been the target of several therapies. Kuai et al. (2015) used mouse embryonic stem cells and induced them to differentiate into oligodendrocyte precursor cells. On PND10, Twitcher mice were injected in the forebrain with cells positive for oligodendrocyte markers. It was hypothesized that these cells would be able to supply active GALC to the CNS and replace the endogenous cells with those of donor origin. Twenty days after injection, the level of myelin was measured, as was the distribution of implanted donor cells. There was no increase in the level of myelin basic protein in treated mice, and the donor cells remained localized to the injection site (Kuai el al., 2015). In addition, there was no improvement in behavioral assays measuring stride length or twitching severity, and lifespan of treated mice was not significantly different from untreated or those injected with saline (Kuai et al., 2015).

\section{Neuronal and Mesenchymal stem cell transplant}

The transplantation of stem cells able to differentiate into neural cells has been explored as a treatment for GLD. NTera2 (NT2) cells are a pluripotent cell line capable of differentiating into neuron-like cells (Croitoru-Lamoury et al., 2006). Mesenchymal stromal cells (MSCs) are derived from either bone marrow or adipose tissue and are able to develop along the neuronal lineage, among others (Safford et al., 2002). Because of their developmental diversity, it was hypothesized that these cells could be used to ameliorate the demyelination phenotype seen in the Twitcher model (Croitoru-Lamoury et al., 2006). Twitcher mice received intracerebral injections of either MSCs or NT2 cells at 24 hours after birth and although transplantation resulted in successful engraftment of each cell type, there was no extension in lifespan (Croitoru-Lamoury et al., 2006). However, both NT2 cells and MSCs were able to differentiate into neurons, oligodendrocytes, and astrocytes by 35 days posttransplantation (Croitoru-Lamoury et al., 2006).

Further studies using MSCs led to the hypothesis that these cells could be used as a treatment to replace dead oligodendrocytes, provide GALC activity, and reduce the inflammatory response associated with GLD (Wicks et al., 2011). Because of the immunosuppressive capabilities of MSCs, it was thought that there may be less neuroinflammation associated with MSC administration, making them a potentially safer therapeutic than BMT. ICV injection of MSCs into mice at PND 3-4 did not greatly improve lifespan. Twitcher mice treated with MSCs survived a mean of approximately 38 days, compared to untreated Twitcher mean survival of approximately 33 days (Ripoll et al., 2011). Despite the minor increase in lifespan, these treated mice performed better than untreated Twitcher mice in several behavioral assays (Ripoll et al., 2011). A reduction in 
inflammatory cytokines and globoid cells was also seen; however, there was no increase in myelin basic protein staining, and GALC activity was not significantly different from that in untreated Twitcher mice (Ripoll et al., 2011). A similar study by Wicks et al., (2011) investigated the effect of MSC administration into the striatum in an effort to increase their effect on motor function. MSC treatment did not significantly reduce disease phenotypes or extend lifespan (Wicks el al. 2011). Miranda et al., (2011) used intravenous (IV) injections of MSCs to determine if signs of disease in the PNS could be ameliorated. Similar to previous studies, the increase in lifespan was minimal, but there was an increase in the number of axons and Schwann cell precursors (Miranda et al., 2011).

\section{Neural stem-cell gene therapy}

There has been limited success using neural stem-cell gene therapy. Strazza et al. (2009) developed a CNS-derived cell line suitable for injection into Twitcher mice. After transducing with a $\gamma$-retroviral gene transfer vector containing the GALC cDNA, the cells were injected into the brains of Twitcher mice at PND2-3 (Strazza et al., 2009). Because the cell line expressed markers for oligodendrocyte progenitors, it was hypothesized that these cells could increase myelination. Treated mice showed a significant reduction in astrocyte gliosis and globoid cells, as wells as an increase in normal-looking oligodendrocytes in close proximity to the injection site. Despite these promising histological results, there was only a minor increase in lifespan, with treated mice living an average of 45 days (Strazza et al., 2009). As with any stem cell-mediated therapy, efficient and stable engraftment must be achieved. In the case of neuronal stem cell-mediated therapy, it would also be beneficial for the donor cells to replace dead or dying neurons and make the proper neuronal connections.

\section{Multi-modality therapies}

Several single-treatment methods resulted in minimal to moderate reductions in the severity of the disease in the Twitcher mouse. Although GLD is a monogenic disease, it has a very complex biochemical, histological, and clinical phenotype. It is likely that the enzymatic deficiency leads to multiple different pathogenic mechanisms that cannot be treated through a single therapy. Therefore, it is not surprising that a single therapy approach is not curative (Table 1). Combining treatment strategies to target multiple pathogenic mechanisms/ pathways has been more successful in pre-clinical testing (Table 2). Combination therapies that target the underlying symptoms, as well as those that supply the deficient enzyme have been focused on for several years. Since HSCT is the standard of care, all of the combination treatments discussed here were performed in conjunction with HSCT.

\section{Substrate reduction therapy + Bone marrow transplant}

Initial studies with L-cycloserine resulted in a minor extension in lifespan and a reduction in astrocytosis (LeVine et al., 2000). It was hypothesized that substrate reduction therapy would decrease psychosine synthesis, and if combined with HSCT, the GALC supplied from donor cells could effectively remove any remaining psychosine (Biswas and LeVine, 2002). Therefore, Twitcher mice were treated with L-cycloserine from PND 3 and received BMT at PND 10. Combination-treated mice lived an average of 112 days, and there was a reduction in globoid cells and gliosis, however, there was no reduction in demyelination (Biswas and 
LeVine, 2002). This combination therapy regimen produced the greatest increase in Twitcher lifespan that had been published at the time.

\section{VEGF + Bone marrow transplant}

The endothelial cell growth factor VEGF was also considered as a candidate for combination therapy with BMT. Due to VEGF's ability to increase microvascular permeability, it was hypothesized that adding VEGF to BMT would enhance the ability of donor-derived cells to cross the blood-brain barrier, thus increasing GALC activity in the CNS. IV delivery of VEGF at PND 1, followed by BMT increased the Twitcher lifespan to a median of 49 days (Young et al., 2004). Although treatment with VEGF resulted in only minor improvements, it provided insights into determining specific aspects of blood-brain barrier permeability.

\section{$\mathrm{N}$-acetyl cysteine + Bone marrow transplant}

Although $\mathrm{N}$-acetyl cysteine alone decreased oxidative stress in treated animals, it resulted in essentially no clinical improvements. However, it was hypothesized that combined with BMT, NAC treatment would have a larger effect (Hawkins-Salsbury et al., 2012).

Heterozygous mothers received NAC in their water during pregnancy, and after birth, Twitcher mice continued to receive NAC both through their water supply, as wells as IP injections thrice weekly (Hawkins-Salsbury et al., 2012). Animals treated with NAC alone had a significant reduction in carbonyls in the brain when compared to untreated Twitchers, however, there was no decrease in the NAC + BMT treatment group (Hawkins-Salsbury et al., 2012). There was also no improvement in myelination or globoid-cell infiltration in the combined therapy group compared to animals receiving BMT alone (Hawkins-Salsbury et al., 2012). Finally, there was no increase in lifespan and very little reduction in reactiveoxygen species in the brains of treated animals (Hawkins-Salsbury et al., 2012). This could be due to the additional oxidative damage conferred by the conditioning irradiation necessary for BMT.

\section{Enzyme replacement + Bone marrow transplant}

Both ERT and BMT alone are able to prolong life in Twitcher mice and reduce some signs of disease. It was hypothesized by Qin et al. (2012) that combining these treatments would compound their effects; ERT would provide high levels of GALC activity shortly after birth, and BMT would provide a lower level but persistent source of the enzyme. GALC was delivered by both intrathecal (IT) and ICV injections within the first 3 days after birth, and BMT was performed the following day (Qin et al., 2012). Although the GALC levels shortly after treatment were significantly greater than WT, at PND 36 there was no difference in activity between untreated and treated Twitcher mice (Qin et al., 2012). Despite this, histological signs of disease, including activated astrocytes and microglia/macrophages, and demyelination, were reduced. Levels of psychosine were also reduced in ERT + BMTtreated animals when measured at PND 36. ERT + BMT treated mice had a median lifespan of 59 days (Qin et al., 2012). 


\section{Gene therapy + Bone marrow transplant}

A combination therapy study using HSCT and a lentiviral vector was performed in the Twitcher mouse. Bone marrow stem cells and a lentiviral vector expressing GALC were IV injected in neonatal Twitcher mice without prior conditioning (Galbiati et al., 2009). This combination approach significantly increased lifespan, improved motor function, and improved myelination. However, axonal degeneration was comparable to untreated Twitcher mice suggesting that GALC deficiency may also mediate direct neurotoxicity (Galbiati et al., 2009).

Although administration of AAV2/5-GALC resulted in several-fold greater-than-normal levels of GALC activity, AAV2/5-GALC by itself resulted in minimal to modest clinical improvements (Lin et al., 2005). However, using AAV2/5-mediated gene therapy in combination with BMT, Lin et al. (2007) were able to extend the Twitcher lifespan to a mean of 104 days. This treatment regimen included IC injections of AAV2/5-GALC on PND 3 followed by BMT (Lin et al., 2007). Combination-treated mice had near 300\% WT levels of brain GALC activity (Lin et al., 2007). In addition, combination-treated animals had fewer globoid cells, and performed better on behavioral tests than those receiving either single therapy alone (Lin et al., 2007).

In a follow-up study, Reddy et al., (2011) added an IT injection to the treatment regimen, in addition to using AAV2/5-GALC IC injections and BMT. GALC activity in the brain was $\sim 5 \times$ greater than WT levels in both AAV2/5-GALC and combination-treatment groups, indicating that the majority of GALC activity is being provided through gene therapy, not BMT (Reddy et al., 2011). Levels of psychosine were significantly reduced in the combination-treated animals, and a reduction in globoid cells was also seen (Reddy et al., 2011). Lifespan of combination-treated animals was also extended to a median of 123 days (Figure 1; Reddy et al., 2011). Interestingly, there was a decrease in activated astrocytes and microglia/macrophages in the brain and spinal cord of Twitcher mice receiving gene therapy and BMT. There was a decrease in CD4 and CD8 T-cells in the brains of AAV2/5-GALC + BMT treated animals, which was not observed in the brains of mice treated with AAV2/5GALC alone, suggesting that BMT may be playing an immunomodulatory role (Reddy et al., 2011). These data suggest that AAV2/5-GALC increases GALC activity, and BMT decreases neuroinflammation, thus resulting in a synergistic effect between these treatments.

More recently, Rafi et al. (2015a) showed similar results, using BMT at PND 9-10 and IV AAVrh10-GALC injections a day later. Although median lifespan was not reported, the combination-treated animals lived much longer than those receiving BMT or gene therapy alone (Rafi et al., 2015a). In addition, the appearance of myelin in combination-treated animals is similar to that in WT mice, and the brain of a 150-day old treated animal had only small numbers of globoid cells (Rafi et al., 2015a).

\section{Gene therapy + Substrate reduction therapy + Bone marrow transplant}

Based on the synergy observed with AAV2/5-GALC gene therapy in combination withBMT, Hawkins-Salsbury et al. (2015) hypothesized that targeting an additional pathway might provide even greater therapeutic efficacy. By combining AAV2/5-mediated gene therapy, 
BMT, and SRT using L-cycloserine, the lifespan of Twitcher mice was significantly increased to a median of $\sim 300$ days (Figure 1; Hawkins-Salsbury et al., 2015). GALC activity in triple-treated mice at 36 days is over $3 \times$ that of WT mice, and only decreases minimally as the animals age (Hawkins-Salsbury et al., 2015). At 160 days, levels of psychosine in triple-treated animals was not significantly different than that measured in WT animals, and these levels remained low at terminal time-points (Hawkins-Salsbury et al., 2015). The number of globoid cells, intensity of GFAP staining, and levels of proinflammatory cytokines were all at WT levels when triple-treated animals were 36 days old. Interestingly, globoid cells and astrocyte activation increased with age, however, cytokine levels remained low (Hawkins-Salsbury et al., 2015). The profound improvement in disease phenotypes is likely attributed to the multiple pathways targeted by the treatments. Gene therapy provides GALC activity to the CNS and PNS, particularly targeting neurons, which can cross-correct oligodendrocytes and other cell types that are not effectively targeted by AAV vectors. L-cycloserine reduces the synthesis of psychosine in oligodendrocytes, and BMT reduces neuroinflammation through immunomodulation. Because GLD is a complex, multifaceted disease, the most effective therapies will likely be those that target both the enzymatic deficiency and secondary pathogenic mechanisms of disease.

\section{Conclusions}

Due to the complexity of disease presentation and pathogenesis, single-modality therapies have thus far only been minimally effective at treating Krabbe disease. Targeting multiple pathogenic mechanisms has been more successful in not only prolonging lifespan, but also in reducing failure to thrive, as measured through behavioral assays. It is likely that future treatments will target multiple pathogenic mechanisms. There has been recent interest in utilizing genome editing in tandem with HSCT, however this approach is unlikely to be successful, since HSCT by itself is only minimally effective in treating GLD. Using other stem cell sources alone also is unlikely to be a viable therapeutic option, since the successful differentiation and integration seen in murine models were unable to produce a significant increase in lifespan. Although some treatments do seem promising, there are still fundamental questions about GLD pathogenesis that need to be addressed in order to develop a truly efficacious treatment.

\section{Acknowledgments}

We thank Yedda Li for critical reading and assistance with creating the figure.

Support or grant information: This work was partially funded by NIH grant R01 NS 084861.

\section{Literature cited}

Andrews JM, Menkes JH. Ultrastructure of experimentally produced globoid cells in the rat. Experimental Neurology. 1970; 29:483-493. [PubMed: 5492920]

Asokan A, Schaffer DV, Samulski RJ. The AAV vector toolkit: Poised at the clinical crossroads. Molecular Therapy. 2012; 20(4):699-708.

Bambach BJ, Moser HW, Blakemore K, Corson VL, Griffin CA, Noga SJ, Perlman EJ, Zuckerman R, Wenger DA, Jones RJ. Case report: Engraftment following in utero bone marrow transplantation for globoid cell leukodystrophy. Bone Marrow Transplantation. 1997; 19:399-402. [PubMed: 9051254] 
Baskin GB, Ratterree M, Davison BB, Falkenstein KP, Clarke MR, England JD, Vanier MR, Luzi P, Rafi MA, Wenger DA. Genetic galactocerebrosidase deficiency (globoid cell leukodystrophy, Krabbe disease) in rhesus monkeys (Macaca mulatta). Laboratory Animal Science. 1998; 48:476482. [PubMed: 10090061]

Baumann N, Pham-Dinh D. Biology of oligodendrocyte and myelin in the mammalian central nervous system. Physiological Reviews. 2001; 81:871-927. [PubMed: 11274346]

Biswas S, LeVine SM. Substrate-reduction therapy enhances the benefits of bone marrow transplantation in young mice with globoid cell leukodystrophy. Pediatric Research. 2002; 51:4047. [PubMed: 11756638]

Caniglia M, Rana I, Pinto RM, Fariello G, Caruso R, Angioni A, Dionidi-Vici C, Sabetta G, De Rossi G. Allogenic bone marrow transplantation for infantile globoid-cell leukodystrophy (Krabbe's disease). Pediatric Transplantation. 2002; 6:427-431. [PubMed: 12390432]

Castelvetri LC, Givogri MI, Zhu H, Smith B, Lopez-Rosas A, Qui X, van Breeman R, Bongarzone E. Axonopathy is a compounding factor in the pathogenesis of Krabbe disease. Acta Neuropathol. 2011; 122(1):35-48. [PubMed: 21373782]

Croitoru-Lamoury J, Williams KR, Lamoury FMJ, Veas LA, Ajami B, Taylor RM, Brew BJ. Neural transplantation of human MSC and NT2 cells in the twitcher mouse model. Cytotherapy. 2006; 8(5): 445-458. [PubMed: 17050249]

Davidson BL, Stein CS, Heth JA, Martins I, Kotin RM, Derksen TA, Zabner J, Ghodsi A, Chiorini JA. Recombinant adeno-associated virus type 2, 4, and 5 vectors: Transduction of variant cell types and regions in the mammalian central nervous system. PNAS. 2000; 97:3428-3432. [PubMed: 10688913]

Deane JE, Graham SC, Kim NN, Stein PE, McNair R, Cachon-Gonzalez MB, Cox TM, Read RJ. Insights into Krabbe disease from structures of galactocerebrosidase. PNAS. 2011; 108(37): 15169-15173. [PubMed: 21876145]

Desnick RJ, Schuchman EH. Enzyme replacement therapy for lysosomal diseases: Lessons from 20 years of experience and remaining challenges. Annual Review of Genomics and Human Genetics. 2012; 13:307-335.

Duchen LW, Eicher EM, Jacobs JM, Scaravilli F, Teixeira F. Hereditary leucodystrophy in the mouse: The new mutant Twitcher. Brain. 1980; 103:695-710. [PubMed: 7417782]

Duffner PK, Barczykowski A, Jalal K, Yan L, Kay DM, Carter RL. Early infantile Krabbe disease: Results of the world-wide Krabbe registry. Pediatric Neurology. 2011; 45:141-148. [PubMed: 21824559]

Escolar ML, Poe MD, Provenzale JM, Richards KC, Allison J, Wood S, Wenger DA, Pietryga D, Wall D, Champagne M, Morse R, Krivit W, Kurtzberg J. Transplantation uf umbilical-cord blood in babies with infantile Krabbe;s disease. The New England Journal of Medicine. 2005; 352:206981. [PubMed: 15901860]

Fiumara A, Barone R, Arena A, Filocamo M, Lissens W, Pavone L, Sorge G. Krabbe leukodystrophy in a selected population with high rate of late onset forms: longer survival linked to c. $121 \mathrm{G}>\mathrm{A}$ (p.Gly21Ser) mutation. Clinical Genetics. 2011; 80:452-458. [PubMed: 21070211]

Fletcher TF, Kurtz HJ. Animal model: Globoid cell leukodystrophy in the dog. American Journal of Pathology. 1972; 66:375-378. [PubMed: 5009979]

Frisella WA, O'Connor LH, Vogler CA, Roberts M, Walkley S, Levy B, Daly TN, Sands MS. Intracranial injection of rrecombinant adeno-associated virus improves cognitive function in a murine model of mucopolysaccharidosis type VII. Mol Ther. 2001; 3:351-358. [PubMed: 11273777]

Galbiati F, Givogri MI, Cantuti L, Rosas AL, Cao H, van Breemen R, Bongarzone ER. Combined hematopoietic and lentiviral gene-transfer therapies in newborn Twitcher mice reveal contemporaneous neurodegeneration and demyelination in Krabbe disease. J Neurosic Res. 2009; 87:1748-1759.

Gentner B, Visigalli I, Hiramatsu H, Lechman E, Ungari S, Giustacchini A, Schira G, Amendola M, Quattrini A, Martino S, Orlacchio A, Dick JE, Biffi A, Naldini L. Identification of hematopoietic stem cell-specific miRNAs enables gene therapy of globoid cell leukodystrophy. Science Translational Medicine. 2010; 2:58ra84. 
Haq E, Giri S, Singh I, Singh AK. Molecular mechanism of psychosine-induced cell death in human oligodendrocyte cell line. Journal of Neurochemistry. 2003; 86:1428-1440. [PubMed: 12950451]

Hawkins-Salsbury J, Qin EY, Reddy AS, Vogler CA, Sands MS. Oxidative stress as a therapeutic target in globoid cell leukodystrophy. Experimental Neurology. 2012; 237:444-452. [PubMed: 22849820]

Hawkins-Salsbury JA, Parameswar AR, Jiang X, Schlesinger PH, Bongarzone E, Ory DS, Demchenko AV, Sands MS. Psychosine, the cytotoxic sphingolipid that accumulates in globoid cell leukodystrophy, alters membrane architecture. Journal of Lipid Research. 2013; 54:3303-3311. [PubMed: 24006512]

Hawkins-Saslsbury JA, Shea L, Jiang X, Hunter DA, Guzman AM, Reddy AS, Qin EY, Li Y, Gray SJ, Ory DS, Sands MS. Mechanism-based combination treatment dramatically increases therapeutic efficacy in murine globoid cell leukodystrophy. The Journal of Neuroscience. 2015; 35:64956505. [PubMed: 25904800]

Hoogerbrugge PM, Poorthuis BJ, Romme AE, van de Kamp JJ, Wagemaker G, van Bekkum DW. Effect of bone marrow transplantation on enzyme levels and clinical course in the neurologically affected Twitcher mouse. J Clinical Investigation. 1988; 81:1790-1794.

Im DS, Heise CE, Nguyen T, O'Dowd BF, Lynch KR. Identification of a molecular target of psychosine and its role in globoid cell formation. The Journal of Cell Biology. 2001; 153:429-434. [PubMed: 11309421]

Jatana M, Giri S, Singh A. Apoptotic positive cells in Krabbe brain and induction of apoptosis in rat C6 glial cells by psychosine. Neuroscience Letters. 2002; 330:183-187. [PubMed: 12231442]

Kagitani-Shimono K, Mohri I, Fujitani Y, Suzuki K, Ozono K, Urade Y, Taniike M. Anti-inflammatory therapy by ibudilast, a phosphodiesterase inhibitor, in demyelination of Twitcher, a genetic demyelination model. Journal of Neuroinflammation. 2005; 2:10. [PubMed: 15813970]

Kobayashi T, Yamanaka T, Jacobs JM, Teixeira F, Suzuki K. The Twitcher mouse: An enzymatically authentic model of human globoid cell leukodystrophy (Krabbe disease). Brain Research. 1980; 202:479-483. [PubMed: 7437911]

Kobayashi T, Shinnoh N, Goto I, Kuroiwa Y. Hydrolysis of galactosylceramide is catalyzed by two genetically distinct acid $\beta$-galactosidases. The Journal of Biological Chemistry. 1985; 260:1498214987. [PubMed: 3934152]

Kobayashi T, Goto I, Yamanaka T, Suzuki Y, Nakano T, Suzuki K. Infantile and fetal globoid cell leukodystrophy: Analysis of galactosylceramide and galactosylsphingosine. Ann Neurol. 1988; 24:517-522. [PubMed: 3239954]

Kohlschütter A. Lysosomal leukodystrophies: Krabbe disease and metachromatic leukodystrophy. Handbook of Clinical Neurology. 2013; 113:1611-1618. [PubMed: 23622382]

Kondo Y, Wenger DA, Gallo V, Duncan ID. Galactocerebrosidase-deficient oligodendrocytes maintain stable central myelin by exogenous replacement of the missing enzyme in mice. PNAS. 2005; 102:18670-18675. [PubMed: 16352725]

Kornfeld S. Structure and function of the mannose 6-phosphate/insulinlike grown factor II receptors. Annu Rev Biochem. 1992; 61:307-330. [PubMed: 1323236]

Krabbe K. A new familial, infantile form of diffuse brain-sclerosis. Brain. 1916; 39(1-2):74-114.

Krivit W, Shapiro EG, Peters C, Wanger JE, Cornu G, Kurtzberg J, Wenger DA, Kolodny EH, Vanier MT, Loes DJ, Dusenbery K, Lockman LA. Hematopoietic stem-cell transplantation in globoid-cell leukodystrophy. The New England Journal of Medicine. 1998; 338:1119-1126. [PubMed: 9545360]

Kuai XL, N RZ, Zhou GX, Mao ZB, Zhang JF, Yi N, Liu ZX, Shao N, Ni WK, Wang ZW. Transplantation of mouse embryonic stem cell-derived oligodendrocytes in the murine model of globoid cell leukodystrophy. Stem Cell Research \& Therapy. 2015; 6:30. [PubMed: 25888852]

Lee WC, Courtenay A, Troendle FJ, Stallings-Mann ML, Dickey CA, DeLucia MW, Dickson DW, Eckman CB. Enzyme replacement therapy results in substantial improvements in early clinical phenotype in a mouse model of globoid cell leukodystrophy. The FASEB Journal. 2005; 19:15491551. [PubMed: 15987783]

Lee WC, Tsoi YK, Dickey CA, DeLucia MW, Dickinson DW, Eckman CB. Suppression of galactosylceramide (GALC) expression in the Twitcher mouse model of globoid cell 
leukodystrophy (GLD) is caused by nonsense-mediated mRNA decay (NMD). Neurobiology of Disease. 2006; 23:273-280. [PubMed: 16759875]

Lee WC, Tsoi YK, Troendle FJ, DeLucia MW, Ahmed Z, Dicky CA, Dickson DW, Eckman CB. Single-dose intracerebroventricular administration of galactocerebrosidase improves survival in a mouse model of globoid cell leukodystrophy. The FASEB Journal. 2007; 21:2520-2527. [PubMed: 17403939]

LeVine SM, Pedechenko TV, Bronshteyn IG, Pinson DM. L-cycloserine slows the clinical and pathological course in mice with globoid cell leukodystrophy (Twitcher mice). Journal of Neuroscience Research. 2000; 60(2):231-236. [PubMed: 10740228]

Lin DS, Fantz CR, Levy B, Rafi MA, Vogler C, Wenger DA, Sands MS. AAV2/5 vector expressing galactocerebrosidase ameliorates CNS disease in the murine model of Globoid-cell leukodystrophy more efficiently than AAV2. Molecular Therapy. 2005; 12:422-430. [PubMed: 15996520]

Lin DS, Donsante A, Macauley S, Levy B, Vogler C, Sands MS. Central nervous system-directed AAV2/5-mediated gene therapy synergizes with bone marrow transplant in the murine model of globoid-cell leukodystrophy. Molecular Therapy. 2007; 15(1):44-52. [PubMed: 17164774]

Luzi P, Rafi MA, Wenger DA. Characterization of the large deletion in the GALC gene found in patients with Krabbe disease. Human Molecular Genetics. 1995; 4:2335-2338. [PubMed: 8634707]

Luzi P, Rafi MA, Victoria T, Baskin GB, Wenger DA. Characterization of the Rhesus monkey Galactocerebrisidase (GALC) cDNA and gene identification of the mutation causing globoid cell leukodystrophy (Krabbe disease) in this primate. Genomics. 1997; 42:319-324. [PubMed: 9192853]

Luzi P, Rafi MA, Zaka M, Curtis M, Vanier MT, Wenger DA. Generation of a mouse with low galactocerebrosidase activity by gene targeting: a new model of globoid cell leukodystrophy (Krabbe disease). Molec Genet Metab. 2001; 73:211-223. [PubMed: 11461188]

Luzi P, Abraham RM, Rafi MA, Curtis M, Hooper DC, Wenger DA. Effects of treatments on inflammatory and apoptotic markers in the CNS of mice with globoid cell leukodystrophy. Brain Research. 2009; 1300:146-158. [PubMed: 19748497]

Miranda CO, Teixeira CA, Liz MA, Sousa VF, Franquinho F, Forte G, Di Nardo P, Pinto-do-O P, Sousa MM. Systemic delivery of bone marrow-derived mesenchymal stromal cells diminishes neuropathology in a mouse model of Krabbe's disease. Stem Cells. 2011; 29:1728-1751.

Miyatake T, Suzuki K. Globoid cell leukodystrophy: Additional deficiency of psychosine galactosidase. Biochemical and Biophysical Research Communications. 1972; 48:538-543.

Neufeld EF, Fratantoni JC. Inborn errors in mucopolysaccharide metabolism. Science. 1970; 169:141146. [PubMed: 4246678]

Paintlia MK, Singh I, Singh AK. Effect of vitamin D3 intake on the onset of disease in murine model of human Krabbe disease. J Neurosici Res. 2015; 93:28-42.

Parenti G, Andria A, Ballabio A. Lysosomal storage diseases: From pathophysiology to therapy. Annu Rev Med. 2015; 66:471-486. [PubMed: 25587658]

Passini MA, Macauley SL, Huff MR, Taksir TV, Bu J, Wu IH, Piepenhagen PA, Dodge JC, Shihabuddin LS, O'Riordan CR, Schuchman EH, Stewart GR. AAV vector-mediated correction of brain pathology in a mouse model of Niemann-Pick A disease. Mol Ther. 2005; 11:754-762. [PubMed: 15851014]

Passini MA, Dodge JC, Bu J, Yang W, Zhao Q, Sondhi D, Hackett NR, Kaminsky SM, Mao Q, Shihabuddin LS, Cheng SH, Sleat DE, Stewart GR, Davidson BL, Lobel P, Crystal RG. Intracranial delivery of CLN2 reduces brain pathology in a mouse model of classical late infantile neuronal ceroid lipofuscinosis. J Neurosci. 2006; 26:1334-1342. [PubMed: 16452657]

Potter GB, Santos M, Davisson MT, Rowitch DH, Marks DL, Bongarzone ER, Petryniak MA. Missense mutation in mouse GALC mimics human gene defect and offers new insights into Krabbe disease. Human Mol Genetics. 2013; 22:3397-3414.

Qin EY, Hawkins-Salsbury JA, Jiang X, Reddy AS, Farber NB, Ory DS, Sands MS. Bone marrow transplantation increases efficacy of central nervous system-derived enzyme replacement therapy 
in the murine model of globoid cell leukodystrophy. Molecular Genetics and Metabolism. 2012; 107:186-196. [PubMed: 22704480]

Rafi MA, Rao HZ, Passini MA, Curtis M, Vanier MT, Zaka M, Luzi P, Wolfe JH, Wenger DA. AAVmediated expression of galactocerebrosidase in brain results in attenuated symptoms and extended life span in murine models of globoid cell leukodystrophy. Molecular Therapy. 2005; 11:734-744. [PubMed: 15851012]

Rafi MA, Rao HZ, Luzi P, Curtis MT, Wenger DA. Extended Normal Life After AAVrh10-mediated Gene Therapy in the Mouse Model of Krabbe Disease. Molecular Therapy. 20(11):2031-2042.

Rafi MA, Rao HZ, Luzi P, Wenger DA. Long-term improvements in lifespan and pathology in CNS and PNS after BMT plus one intravenous injection of AAVrh10-GALC in Twitcher mice. Molecular Therapy. 2015a; 23:1681-1690. [PubMed: 26329589]

Rafi MA, Rao HZ, Luzi P, Luddi A, Curtis MT, Wenger DA. Intravenous injection of AAVrh10-GALC after the neonatal period in twitcher mice results in significant expression in the central and peripheral nervous systems and improvement of clinical features. Molecular Genetics and Metabolism. 2015b; 114(3):459-466. [PubMed: 25533112]

Reddy AS, Kim JH, Hawkins-Salsbury JA, Macauley SL, Tracy ET, Vogler CA, Han X, Song SK, Wozniak DF, Fowler SC, Klein RS, Sands MS. Bone marrow transplantation augments the effect of brain- and spinal cord-directed adeno-associated virus $2 / 5$ gene therapy by altering inflammation in the murine model of globoid-cell leukodystrophy. Journal of Neuroscience. 2011; 31(27):9945-9957. [PubMed: 21734286]

Ripoll CB, Flaat M, Klopf-Eiermann J, Fisher-Perkins JM, Trygg CB, Scruggs BA, McCants ML, Leonard HP, Lin AF, Zhang S, Eagle ME, Alverez Z, Li YT, Li SC, Gimble JM, Bunnell BA. Mesenchymal lineage stem cells have pronounced anti-inflammatory effects in the Twitcher mouse model of Krabbe's disease. Stem Cells. 2011; 29:67-77. [PubMed: 21280158]

Safford KM, Hicok KC, Safford SD, Halvorsen YC, Wilkison WO, Gimble JM, Rice HE. Neurogenic differentiation of murine and human adipose-derived stromal cells. Biochemical and biophysical Research Communications. 2002; 294:371-379. [PubMed: 12051722]

Sakai N, Inui K, Tatsumi N, Fukushima H, Nishigaki T, Taniike M, Nishimoto J, Tsukamoto H, Yanagihara I, Ozono K, Okada S. Molecular cloning and expression of cDNA for murine galactocerebrosidase and mutation analysis of the Twitcher mouse, and model of Krabbe's disease. Journal of Neurochemistry. 1996; 66:1118-1124. [PubMed: 8769874]

Skorupa AF, Fisher KJ, Wilson JM, Parente MK, Wolfe JH. Sustained production of $\beta$-glucuronidase from localized sites after AAV vector gene transfer results in widespread distribution of enzyme and reversal of lysosomal storage lesions in a large volume of brain in mucopolysaccharidosis VII mice. Exp Neurol. 1999; 160:17-27. [PubMed: 10630187]

Strazza M, Luddi A, Carbone M, Rafi MA, Costantino-Ceccarini E, Wegner DA. Significant correction of pathobiology in brains of Twitcher mice following injection of genetically modified mouse neural progenitor cells. Molecular Genetics and Metabolism. 2009; 97:27-34. [PubMed: 19217332]

Sundaram KS, Lev M. Inhibition of sphingolipid synthesis by cycloserine in vitro and in vivo. Journal of Neurochemistry. 1984; 42:577-581. [PubMed: 6693888]

Suzuki K, Suzuki Y. Globoid cell leukodystrophy (Krabbe's disease): deficiency of galactocerebrosidase $\beta$-galactosidase. Proc Natl Acad Sci USA. 1970; 66:302. [PubMed: 5271165]

Suzuki K, Suzuki K. The Twitcher mouse: A model of human globoid cell leukodystrophy (Krabbe's Disease). The American Journal of Pathology. 1983; 111:394-397. [PubMed: 6859223]

Suzuki K. Globoid cell leukodystrophy (Krabbe's disease): Update. J Child Neurol. 2003; 18:595-603. [PubMed: 14572137]

Suzumura A, Ito A, Yoshikawa M, Sawada M. Ibudilast suppresses TNFa production by glial cells functioning mainly as type III phosphodiesterase inhibitor in the CNS. Brain Research. 1999; 837:203-212. [PubMed: 10434004]

Tanaka K, Webster HD. Effects of Psychosine (Galactosylsphingosine) on the survival and the fine structure of cultured Schwann cells. Journal of Neuropathology and Experimental Neurology. 1993; 52(5):490-498. [PubMed: 8360702] 
Taniike M, Suzuki K. Spacio-temporal progression of demyelination in Twitcher mouse: With clinicpathological correlation. Acta Neuropathol. 1994; 88:228-236. [PubMed: 7528964]

Tappino B, Biancheri R, Mort M, Regis S, Corsolini F, Rossi A, Stroppiano M, Lualdi S, Fiumara A, Bembi B, Di Rocco M, Cooper DN, Filocamo M. Identification and characterization of 15 novel GALC gene mutations causing Krabbe disease. Human Mutation. 2010; 31(12):E1894-1915. [PubMed: 20886637]

Teixeira CA, Miranda CO, Sousa VF, Santos TE, Malheiro AR, Solomon M, Maegawa GH, Brites P, Sousa MM. Early axonal loss accompanied by impaired endocytosis, abnormal axonal transport, and decreases microtubule stability occur in the model of Krabbe's disease. Neurobiology of disease. 2014; 66:92-103. [PubMed: 24607884]

Tohyama J, Vanier MT, Suzuki K, Ezoe T, Matsuda J, Suzuki K. Paradoxical influence of acid $\beta$ galactosidase gene dosage on phenotype of the twitcher mouse (genetic galactosylceramidase deficiency). Hum Mol Genet. 2000; 9:1699-1707. [PubMed: 10861297]

Victoria T, Rafi MA, Wenger DA. Cloning of the canine GALC cDNA and identification of the mutation causing globoid cell leukodystrophy in West Highland and Cairn Terriers. Genomics. 1996; 33:457-462. [PubMed: 8661004]

Wenger DA, Victoria T, Rafi MA, Luzi P, Vanier MT, Vite C, Patterson DF, Haskins MH. Globoid cell leukodystrophy in Cairn and West Highland white terriers. The American Genetic Association. 1999; 90:138-142.

White AB, Givogri MI, Lopez-Rosas A, Cao H, van Breemen R, Thinakaran G, Bongarzone ER. Psychosine accumulates in membrane microdomains in the brain of Krabbe patients, disrupting the raft architecture. The Journal of Neuroscience. 2009; 29:6068-6077. [PubMed: 19439584]

Wicks SE, Londot H, Zhang B, Dowden J, Klopf-Eiermann J, Fisher-Perkins JM, Trygg CB, Scruggs BA, Zhang X, Gimble JM, Bunnell BA, Pistell PJ. Effect of intrastriatal mesenchymal stromal cell injection on progression of a murine model of Krabbe disease. Behavioural Brain Research. 2011; 225:415-425. [PubMed: 21840342]

Won JS, Kim J, Paintila MK, Singh I, Singh AK. Role of endogenous psychosine accumulation in oligodendrocyte differentiation and survival: Implication for Krabbe disease. Brain Research. 2013; 1508:44-52. [PubMed: 23438514]

Yeager AM, Brennan S, Tiffany C, Moser HW, Santos GW. Prolonged survival and remyelination after hematopoietic cell transplantation in the Twitcher mouse. Science. 1984; 225:1052-1054. [PubMed: 6382609]

Young PP, Fantz CR, Sands MS. VEGF disrupts the neonatal blood-brain barrier and increases life span after non-ablative BMT in a murine model of congenital neurodegeneration caused by a lysosomal enzyme deficiency. Experimental Neurology. 2004; 188:104-114. [PubMed: 15191807]

Zaka M, Wenger DA. Psychosine-induced apoptosis in a mouse oligodendrocyte progenitor cell line is mediated by caspase activation. Neuroscience Letters. 2004; 358:205-209. [PubMed: 15039117] 


\section{Statement of Significance}

Krabbe disease was first described one hundred years ago, and the primary animal model, the Twitcher mouse, has been studied for almost 40 years. Despite the long-standing awareness of the disease and its genetic cause, there is still no effective treatment. While hematopoietic stem cell transplantation is the current standard of care for Krabbe patients, it is only effective at slowing disease progression, and only if initiated prior to symptom onset. Recent developments using multi-modality therapies have been more successful than any single-modality therapy. It is likely that combining treatments which target multiple pathogenic mechanisms/pathways will lead to more effective treatments that can be translated into the clinic. 


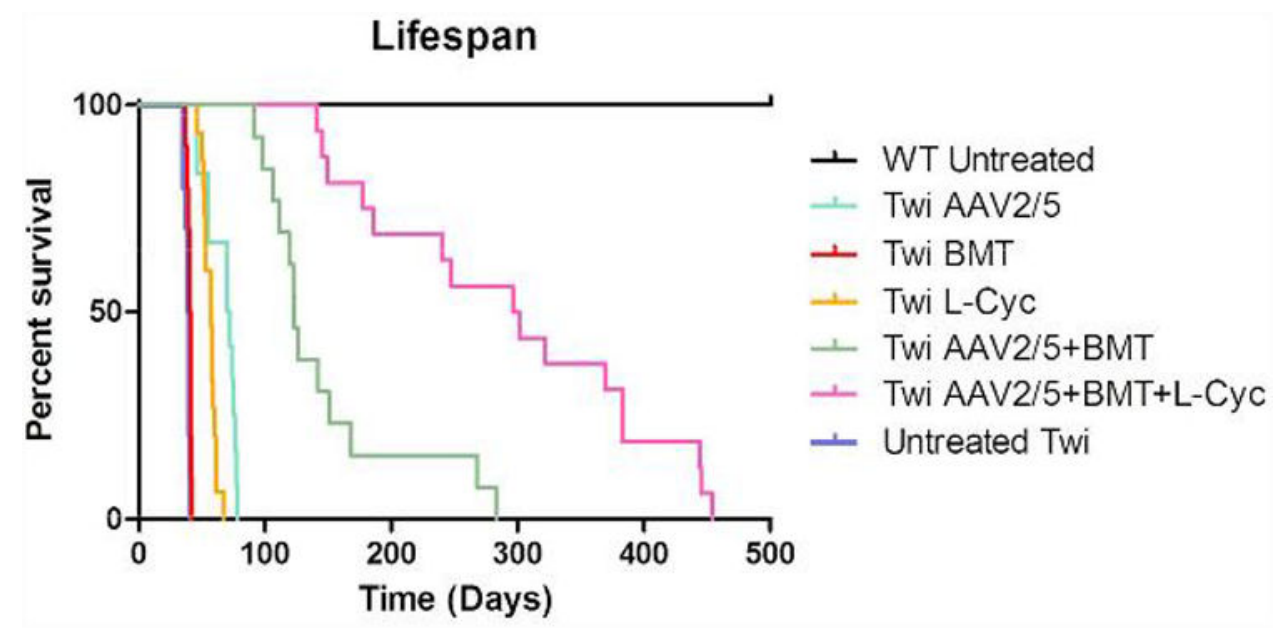

Figure 1.

Kaplan-Meier curve of Twitcher and wild-type mouse lifespan. Twitcher mice treated with a multi-modality therapy survived significantly longer than those treated with a singlemodality therapy (Reddy et al., 2011; Hawkins-Salsbury et al., 2015). The median lifespan of untreated, BMT-treated, AAV2/5-treated, and L-cycloserine-treated Twitcher mice are 39.5, 40.5, 71, and 58 days, respectively. The median lifespan for Twitcher mice treated with AAV2/5+BMT or AAV2/5+BMT+L-cycloserine are 123 and 298.5 days, respectively. 


\section{Table I}

\section{Single Modality Therapies}

\begin{tabular}{|c|c|c|c|}
\hline Therapy & Therapeutic mechanism & Life span increase (days) ${ }^{*}$ & Reference \\
\hline \multirow[t]{2}{*}{ BMT } & Cross -correction & 40 & Yeager et al., 1984 \\
\hline & Immunomodulation & 25 & $\begin{array}{l}\text { Hoogerbrugge et al., } \\
1988\end{array}$ \\
\hline \multirow[t]{3}{*}{ Enzyme replacement therapy } & Short-term replacement of GALC activity & 7 & Lee et al., 2005 \\
\hline & & 5.5 & Lee et al., 2007 \\
\hline & & 11 & Qin et al., 2012 \\
\hline \multirow[t]{5}{*}{ Viral-mediated gene therapy } & Long-term replacement of GALC activity & $\sim 12$ & Rafi et al., 2005 \\
\hline & & 14 & Lin et al., 2005 \\
\hline & & 30 & Reddy et al., 2011 \\
\hline & & 1V:15, ICV+IC:41, ICV+IC+IV:63 & Rafi et al., 2012 \\
\hline & & $\sim 23$ & Rafi et al., 2015b \\
\hline \multirow{2}{*}{$\begin{array}{l}\text { Substrate reduction therapy (L- } \\
\text { cycloserine) }\end{array}$} & Reduce psychosine accumulation & 13 & LeVine et al., 2000 \\
\hline & & 17.5 & $\begin{array}{l}\text { Hawkins-Salsbury et } \\
\text { al., } 2015\end{array}$ \\
\hline Ibudilast & Anti-inflammatory & None & $\begin{array}{l}\text { Kagitani-Shimono et } \\
\text { al., } 2005\end{array}$ \\
\hline Indomethadn & Anti-inflammatory & $\sim 10-12$ & Luzi et al., 2009 \\
\hline Ibuprofen & Anti-inflammatory & $\sim 10-12$ & Luzi et al., 2009 \\
\hline Minocycline & Anti-inflammatoty, neuroprotective & $\sim 10-12$ & Luzi et al., 2009 \\
\hline Vitamin D & Antioxidant & 16 & Paintlia et al., 2015 \\
\hline $\mathrm{N}$-acetylcysteine (NAC) & Antioxidant & None & $\begin{array}{l}\text { Hawkins-Salsbury et } \\
\text { al., } 2012\end{array}$ \\
\hline Neural stem cell gene therapy & Enzyme expression & 7 & Strazza et aL., 2009 \\
\hline Oligodendrocyte transplant & Enzyme expression, myclination & None & Kuai et al., 2015 \\
\hline \multirow[t]{4}{*}{$\begin{array}{l}\text { Neuronal stem cell transplant, } \\
\text { Mesenchymal stromal cells }\end{array}$} & $\begin{array}{l}\text { Enzyme activity, anti-inflammatory, } \\
\text { myelin loss }\end{array}$ & None & $\begin{array}{l}\text { Croitoru-Lamoury et } \\
\text { al., } 2006\end{array}$ \\
\hline & & 5 & Ripoll et al., 2011 \\
\hline & & None & Wicks et al., 2011 \\
\hline & & 2 & Miranda et al., 2011 \\
\hline
\end{tabular}

* Life span increase was calculated as die difference in life span of treated mice and untreated mice, specific to each study. If mean or median life span was not reported in reference text, median lifespan was estimated from Kaplan-Meier curve. 


\section{Table II}

\section{Multimodality Therapies}

\begin{tabular}{llcc}
\hline Therapy & Therapeutic mechanism & $\begin{array}{c}\text { Life span } \\
\text { increase } \\
\text { (days) }\end{array}$ & Reference \\
\hline $\begin{array}{l}\text { Substrate reduction dierapy } \\
+ \text { BMT }\end{array}$ & Reduce psychosine accumulation, cross-correction, immunomodulation & 75 & $\begin{array}{c}\text { Biswas and LeVine, } \\
2002\end{array}$ \\
VGEF - BMT & Cross-correction, immunomodulation & 8.5 & Young et al., 2004 \\
NAC - BMT & Anti-inflammatory, cross-correction, immunomodulation & 1.5 & $\begin{array}{l}\text { Hawkins-Salsbury et } \\
\text { al., 2012 }\end{array}$ \\
$\begin{array}{l}\text { Enzyme replacement } \\
\text { therapy + BMT }\end{array}$ & Short-term replacement of GALC activity, immunomodulation & 19 & Qin et al., 2012 \\
$\begin{array}{l}\text { Viral-mediated gene } \\
\text { dierapy + BMT }\end{array}$ & Long-term replacement of GALC activity, immunomodulation & $\sim 34$ & Galbiati et al., 2009 \\
& & 65 & Lin et al., 2007 \\
& & 82 & Reddy et al., 2011 \\
$\begin{array}{l}\text { Viral-mediated gene } \\
\text { dierapy + Substrate } \\
\text { reduction therapy + BMT }\end{array}$ & $\begin{array}{l}\text { Long-term replacement of GALC activity, reduce psychosine } \\
\text { accumulation, immunomodulation }\end{array}$ & NR & Rafi et al., 2015a \\
\hline $\begin{array}{l}\text { Life span increase was calculated as the difference in life span of treated mice and untreated mice, specific to each study. If mean or median life } \\
\text { span was not reported in reference text, median life span was estimated from Kaplan-Meier curve. }\end{array}$ & 259 & $\begin{array}{l}\text { Hawkins-Salsbury et } \\
\text { al., 2015 }\end{array}$
\end{tabular}

J Neurosci Res. Author manuscript; available in PMC 2017 November 01. 